\title{
The relationship between Gratitude and Life Satisfaction in a sample of Spanish university students: The moderation role of gender
}

\author{
Carmen Salvador-Ferrer \\ Universidad de Almería (Spain)
}

\begin{abstract}
Título: Relación entre la gratitud y la satisfacción con la vida en una muestra de Estudiantes Españoles: El papel moderador del género.

Resumen: El presente estudio pretende examinar la relación entre la gratitud y la satisfacción vital en una muestra de estudiantes universitarios españoles. En esta investigación se utilizó la escala de Gratitud (GQ-6; McCullough et al., 2002) y la escala de Satisfacción con la vida (SWLS; Diener et al., 1985). Los datos, del análisis de regresión lineal, mostraron que la gratitud predice la satisfacción con la vida (en el bienestar físico y psicológico). Por otro lado, en la relación entre ambos términos, se encontraron diferencias de género. Al final del trabajo, se exponen unas conclusiones y, también, se discuten las limitaciones del presente estudio.
\end{abstract}

Palabras clave: gratitud; satisfacción con la vida; género; estudiantes universitarios; España.

\section{Introduction}

Gratitude is a construct which has inspired interest in most researchers because it has been considered an important factor of human personality and social life (Emmons \& McCullough, 2003; Gallup, 1998). Gratitude could refer to a subjective feeling of wonder and appreciation for life (Emmons \& Shelton, 2002). Rosenberg (1998) argued that gratitude is a form of affective experience, defined as "a stable predisposition toward certain types of emotional responding" (p. 249). McCullough, Emmons, \& Tsang (2002) have defined gratitude as "the grateful disposition as a generalized tendency to recognize and respond with grateful emotion" (p.112). There are elements of this grateful disposition (McCullough, Emmons, \& Tsang, 2002) which are named as: intensity, frequency, span or number of life circumstances for which a person feels gratitude, and density or number of individuals who feel grateful. Bertocci and Millar (1963) have defined this as "the willingness to recognize the unearned increments of value in one's experience" (p. 389). Sansone and Sansone (2010) have considered that, depending on the context, gratitude can have different meanings. For example, gratitude could be considered as a habit, an attitude, a coping response and an emotion (Emmons, McDullough, \& Tsang, 2003; Lambert, Graham, \& Fincham, 2009). Meanwhile, as an emotion, Lazarus and Lazarus (1994) argued that gratitude represents the "empathic emotions". Moreover, Seligman (2002) has defined this construct as "a sense of thankfulness and joy in response to receiving a gift, whether the gift be a tangible benefit from a specific other or a moment of peaceful bliss evoked by natural beauty" (cited by Peterson \& Seligman, 2004, p. 554). So, Seligman, Steen, Park, and

* Correspondence address [Dirección para correspondencia]: Carmen María Salvador Ferrer. Universidad de Almería. Carretera Sacramento. La Cañada de San Urbano, s/n. 04120 Almería (Spain). E-mail: cmsalva@ualm.es
Abstract: The aim of this study is to examine the relationship between gratitude and life satisfaction among university students in Spain. The present study seeks to assess gratitude by means of a self-report Gratitude Questionnaire (GQ-6; McCullough et al., 2002) and Life Satisfaction scale (SWLS; Diener et al., 1985). Using a multiple linear regression analysis, the relationship between life satisfaction and gratitude is analyzed. The results suggest that gratitude significantly predicts life satisfaction (on psychological and physical well-being), while on the other hand, differences exist with regard to gender in the relationship between gratitude and life satisfaction. The significance and limitations of the present findings are discussed.

Key words: gratitude; life satisfaction; gender; university students; Spain;

Peterson (2005) have established that gratitude is also associated with life satisfaction.

Along these lines, a number of empirical studies have shown that a significant relation exists between gratitude and life satisfaction and in some research works gratitude is even regarded as a robust predictor of life satisfaction (Algoe, Haidt, \& Gable, 2008; Emmons \& McCullough, 2003; Froh, Yurkewicz, \& Kashdan, 2009; Lavy \& Littman-Ovadia, 2011; Lambert, Clark, Durstchi, Fincham, \& Graham, 2010; Lyubomirsky, Dickershoof, Boehm, \& Sheldon, 2011; McCullough, Emmons, \& Tsang, 2002; McCullough, Tsang \& Emmons, 2004; Toepfer, Cichy, \& Peter, 2012; Watkins, Woodward, Stone, \& Kolts, 2003; Wood, Joseph, \& Maltby, 2009; Wood, Joseph \& Linley, 2007a; Wood, Joseph, \& Maltby, 2009; Wood, Froh, \& Geraghty, 2010). Thus, gratitude could be considered as an adaptive psychological strategy by which human beings interpret their everyday experiences and at the same time receive its benefits. Furthermore, some authors (Boehm, Lyubomirsky, \& Sheldon, 2011; Lyubomirsky \& Layous, 2013) have demonstrated the positive effect of gratitude on life satisfaction.

Life satisfaction has been defined by Diener, Oishi, and Lucas (2003) as people's global cognitive evaluation of their satisfaction with their own lives. As a positive experience, gratitude could change the negative effects of other occurrences in people's existence, leading to higher life satisfaction (Diener, 1984). Seligman (2002) has defined life satisfaction as a cognitive component of subjective well-being which reflects a present satisfaction with one's life. It has been defined as a "judgmental process in which individuals assess the quality of their lives on the basis of their own unique set of criteria" (Pavot \& Diener 1993, p. 164).

On the other hand, research into gratitude has to consider individual differences. Thus, there are studies which deal with certain variables, such as gender. The results from some research work show that scores differ by gender (Froh et al., 2009). The data from these studies on gender difference, in- 
dicate that females are more grateful than males (Chen, Chen, \& Tsai, 2012; Froh et al., 2009; Kashdan, Uswatte, \& Julian, 2006; Sun \& Kong, 2013). This is probably because males consider that to express gratitude is evidence of their vulnerability and that by showing gratitude they could be perceived as weaker and less masculine, therefore, lose their social status (Levant \& Kopecky, 1995; Sun \& Kong, 2013). Most studies show that there is a relationship between gratitude and life satisfaction. However, the mechanisms involved in this relationship are not clear (Sun \& Kong, 2013). Moreover, it is important to study this association because there are few researches in Spain. Therefore, the aim of this project is to study the relationship between gratitude and life satisfaction among university students in Spain. Based on previous studies, we propose the following hypothesis: In the first place, we believe that gratitude is significantly correlated with the life satisfaction (Diener, 1984; Seligman, 2002) of a sample of university undergraduates in Spain. Actuality, there are some studies which have also been examined the associating between gratitude and life satisfaction, like Seligman, Steen, Park and Peterson (2005) and McCullogh et al. (2002). Also, Froh et al. (2009) demonstrated that gratitude has a stronger relation with life satisfaction. Fagley (2012) has shown a positive connection between gratitude and life satisfaction. Therefore, people with tendency to be grateful also report greater life satisfaction (Fagley, 2012).

In the second place, it is our opinion that probably the relationship between gratitude and life satisfaction differ by gender (Froh, Yurkewicz, \& Kashdan, 2009; Sun \& Kong, 2013). Froh et al. (2009) and Naito, Wangwan and Tani (2005) have shown that women reported more gratitude than men. Also, Bono and Froh (2009) prompted to value if gender moderated the relationship between gratitude and subjective well-being. Moreover, they demonstrated the negative relationship of these concepts. Watkins et al. (2003) showed the stronger correlation of gratitude with life satisfaction.

In and other hand, Sun and Kong (2013) argued that it is not very clear the relationship between gratitude and life satisfaction differ by gender. It is the most probably to get a positive relationship between life satisfaction and gratitude, because gratitude is a positive emotion and it is strongly relate to positive experiences (Sun \& Kung, 2013). However, it is possible to find negative relation, too (Emmons and McCullough, 2003; Froh et al., 2009; Kashdan et al., 2006; Watkin et al., 2003; Wood, Maltby, Gillett, Linley, \& Joseph, 2008).

\section{Method}

\section{Participants}

A total of 309 Spanish university students participated in this study. They were selected for convenience by non probabilistic sampling accessibility with a confidence level of $95 \%$. The sample included a slightly larger number of female students $(75 \%)$ compared with $25 \%$ male students. Their ages ranged from 17 to 56, the average age being 21.58 (SD $=4.85)$. The participants were students of different disciplines (44\% of Psychology, 27\% of Social work, $17 \%$ of Social Education and $12 \%$ of Physical Education).

\section{Instruments}

Gratitude. Gratitude Questionnaire (GQ-6) was prepared by McCullough et al. (2002). This instrument measures gratitude as a dispositional trait and assesses four of its facets: intensity, frequency, density, and span of gratitude felt and shared. GQ-6 is a 7-point Likert scale, ranging from 1 (strongly disagree) to 7 (strongly agree). Moreover, there are two negatively worded items (3 "When I look at the world, I do not see much to be grateful for", and 6" Long periods of time can go by before I feel grateful to something or someone"), therefore, a reverse-scoring of these items is necessary. The reliability is .802 .

Satisfaction with life. Life satisfaction Scale (SWLS) developed by Diener, Emmons, Larsen and Griffin (1985). This scale contains five items which evaluate the cognitive judgments of an individual's own life. Items are rated on a 5point Likert- type scale ( $1=$ strongly disagree, $5=$ strongly agree; sample item, "I am satisfied with my life").The reliability is . 773 .

\section{Procedure}

Participants completed the questionnaires in the classroom. Before completing the measure, a researcher informed them about this research work and, at the same time, assured them of the confidentiality of their response. Instruments took approximately $20 \mathrm{~min}$ to complete.

\section{Results}

Descriptive statistics and correlations are reported in Table 1. In this table, we can see lower values in life satisfaction (General Mean $=2.4 ; S D=.71 ;$ Men: Gratitude Mean $=5.60$ and $S D=1.04 ;$ Women: Gratitude Mean $=5.62$ and $S D=$ $1.01)$ and moderate values in gratitude (General Mean $=5.60$; $S D=1.0 ;$ Men: Satisfaction Mean $=2.27$ and $S D=.62 ; \mathrm{Wom}$ $e n$ : Satisfaction Mean $=2.50$ and $S D=.75$ ).

In the gratitude scale, most of the data appear in GQ5 "As I get older I find myself more able to appreciate the people, events, and situations that have been part of my life history" $(M=6 ; S D=1.32)$. In the life satisfaction is SWLS 5 "If I could live my life over, I would change almost nothing" the most highly valued of the scale $(M=2.8 ; S D=1.2)$.

Table 1 shows inter-correlations between each of the scales. In this table, the Pearson correlations more than all the other measures show that there is a significant negative correlation between gratitude and life satisfaction $(r=-.187$; $p<.01)$. In both samples, most intra correlations were significant and there were also important negative intercorrelations, as in GQ1 "I have so much in life to be thank- 
ful for" vs. SWLS 5 "If I could live my life over, I would change almost nothing" $(r=-.33 ; p<.05)$, and GQ2 "If I had to list everything that I felt grateful for, it would be a very long list" vs. SWLS 5 "If I could live my life over, I would change almost nothing" $(r=-.34 ; p<.05)$.

Table 1. Descriptive statistics and correlations for all measures.

\begin{tabular}{|c|c|c|c|c|c|c|c|c|c|c|c|c|c|c|c|}
\hline & $M$ & $S D$ & 1 & 2 & 3 & 4 & 5 & 6 & 7 & 8 & 9 & 10 & 11 & 12 & 13 \\
\hline 1. GRATITUDE & 5.6 & 1.0 & 1 & & & & & & & & & & & & \\
\hline 2. GQ1. & 5.7 & 1.6 & $.86^{* *}$ & 1 & & & & & & & & & & & \\
\hline 3. GQ2. & 5.3 & 1.63 & $.87 * *$ & $.834 * *$ & 1 & & & & & & & & & & \\
\hline 4. GQ3. & 5.7 & 1.14 & $.43^{* *}$ & .211 & .254 & 1 & & & & & & & & & \\
\hline 5. GQ4. & 5.0 & 1.57 & $.79 * *$ & $.619 * *$ & $.646^{* *}$ & .287 & 1 & & & & & & & & \\
\hline 6. GQ5. & 6.0 & 1.32 & $.823 * *$ & $.637 * *$ & $.657 * *$ & .232 & $.565^{* *}$ & 1 & & & & & & & \\
\hline 7. GQ6. & 5.7 & 1.18 & $.506 * *$ & $.306^{* *}$ & .249 & .136 & .265 & $.393^{* *}$ & 1 & & & & & & \\
\hline 8.SATISFACTION & 2.4 & .71 & $-.187^{*}$ & -.31 & $-.31 *$ & -.06 & -.16 & .105 & -.06 & 1 & & & & & \\
\hline 9. SWLS 1. & 2.5 & .95 & -.02 & .02 & -.06 & -.11 & -.13 & .184 & -.04 & $.683^{* *}$ & 1 & & & & \\
\hline 10. SWLS 2. & 2.5 & .99 & -.20 & -.264 & -.27 & -.14 & -.16 & .006 & -.02 & $.698 * *$ & $.318^{*}$ & 1 & & & \\
\hline 11. SWLS 3. & 2.0 & .82 & -.04 & -.237 & -.06 & .07 & .07 & .09 & -.105 & $.662 * *$ & .274 & $.378 * *$ & 1 & & \\
\hline 12. SWLS 4. & 2.2 & .92 & -.09 & -.210 & -.25 & -.08 & -.09 & .137 & .145 & $.540^{* *}$ & .253 & .153 & .271 & 1 & \\
\hline 13. SWLS 5. & 2.8 & 1.2 & -.24 & $-.33^{*}$ & $-.34 *$ & .03 & -.19 & -.007 & -.155 & $.843^{* *}$ & $.522 * *$ & $.529 * *$ & $.470 * *$ & .240 & 1 \\
\hline
\end{tabular}

${ }^{* *} p<.01 ; * p<.05$

Table 2 shows the results of the multivariate regression analysis (lineal method) for the variables predicting life satisfaction. As this table shows, the results obtained are between medium $\left(R^{2}=.105\right)$ and large effect sizes $\left(R^{2}=.447\right)$ as recommended by Field (2009).

Table 2. Coefficient of regression of factors by gender.

\begin{tabular}{|c|c|c|c|c|c|c|c|}
\hline & \multicolumn{7}{|c|}{ Unstandardized coefficients Standardized coefficients } \\
\hline & Factors & $B$ & Std. Error & Beta & $t$ & $p$ & \\
\hline \multirow{7}{*}{ Male+Female } & (constant) & 2.45 & .407 & & 6.02 & .000 & $R^{2}=.215$ \\
\hline & GQ 1. & -.151 & .063 & -.335 & -2.39 & .018 & $F=5.82$ \\
\hline & GQ 2. & -.103 & .066 & -.234 & -1.56 & .121 & $p<.000$ \\
\hline & GQ 3. & .020 & .053 & .032 & .378 & .706 & \\
\hline & GQ 4. & -.027 & .045 & -.059 & -.592 & .555 & \\
\hline & GQ 5. & .207 & .055 & .378 & 3.77 & .000 & \\
\hline & GQ 6. & .035 & .051 & .058 & .693 & .490 & \\
\hline \multirow{7}{*}{ Male } & (constant) & 2.68 & .594 & & 4.51 & .000 & $R^{2}=.313$ \\
\hline & GQ 1. & -.124 & .097 & -.318 & -1.27 & .208 & $F=3.03$ \\
\hline & GQ 2. & -.159 & .097 & -.421 & -1.65 & .111 & $p<.015$ \\
\hline & GQ 3. & -.008 & .081 & -.013 & -.095 & .924 & \\
\hline & GQ 4. & -.015 & .078 & -.035 & -.193 & .848 & \\
\hline & GQ 5. & .267 & .078 & .648 & 3.43 & .001 & \\
\hline & GQ 6. & -.055 & .080 & -.099 & -.689 & .495 & \\
\hline \multirow{7}{*}{ Female } & (constant) & 2.40 & .571 & & 4.21 & .000 & $R^{2}=.472$ \\
\hline & GQ 1. & -.172 & .085 & -.347 & -2.02 & .047 & $F=3.73$ \\
\hline & GQ 2. & -.108 & .090 & -.228 & -1.19 & .236 & $p<.003$ \\
\hline & GQ 3. & .054 & .073 & .083 & .742 & .460 & \\
\hline & GQ 4. & -.035 & .059 & -.075 & -.585 & .560 & \\
\hline & GQ 5. & .192 & .079 & .300 & 2.42 & .017 & \\
\hline & GQ 6. & .076 & .068 & .124 & 1.11 & .267 & \\
\hline
\end{tabular}

Note. Dependent variable $=$ Life satisfaction.

When gender differences were not considered, there was a significant relationship between gratitude and life satisfaction, as in, GQ1 "I have so much in life to be thankful for" $(\beta=-.335, p<.018)$ and GQ5 "As I get older I find myself more able to appreciate the people, events, and situations that have been part of my life history" $(\beta=.378, p<.000)$.

When gender differences are considered, these are significant, too. Thus, results show that in Female participants scores were significantly higher $(p<.003)$ than in male ones $(p<.015)$. Particularly, in Male participants scores reached higher levels in GQ5 "As I get older I find myself more able to appreciate the people, events, and situations that have been part of my life history" $(\beta=.648, p<.011)$ predicted life satisfaction. In female students, there were lower levels of GQ1 "I have so much in life to be thankful for" $(\beta=$ $.347, p<.047$ ) and higher levels of GQ5 "As I get older I 
find myself more able to appreciate the people, events, and situations that have been part of my life history" $(\beta=.300, p$ $<$.017) predicted life satisfaction.

Note that gratitude predicted life satisfaction in both female and male. However, in the male GQ5 "As I get older I find myself more able to appreciate the people, events, and situations that have been part of my life history" is a more significant positive prediction than in females. Also, GQ1 "I have so much in life to be thankful for" predicts lower levels of life satisfaction in females.

\section{Discussion}

In the present study we investigate the relationship between gratitude and life satisfaction among Spanish university students. As expected, correlation analyses showed that gratitude is linked to life satisfaction. However, association analyses shown that there was a negatively significant relationship between gratitude and life satisfaction, Froh et al. (2009) found similar data. Therefore, those with high gratitude levels tend to experience a lower degree of life satisfaction and also those with high life satisfaction levels tend to experience a lower degree of gratitude. This study also supports the theory that gratitude has a significant effect on life satisfaction in accordance with other studies (Bono, Emmons, \& McCullough, 2004; Emmons \& Crumpler, 2000; Emmons \& McCullough, 2003; Froh et al., 2009; Kashdan, Uswatte, \& Julian, 2006; Lyubomirsky, Sheldon, \& Schkade, 2005; Watkins, 2004; Watkins, Woodward, Stone, Kolts, 2003; Wood, Joseph, \& Linley, 2007b; Wood, Maltby, Gillett, Linley, \& Jospeh, 2008).

However, in our research work, we found that gratitude affects life satisfaction negatively and significantly. One possible explanation for these data could be "schematic hypothesis" which suggests that gratitude is caused by receiving help that is appraised as costly to provide, valuable and altruistically offered (Lane \& Anderson, 1976; McCulloguh, Kilpatrick, Emmons, \& Larson, 2001). That is, perceptions of cost, value and altruism could influence the relationship between gratitude and life satisfaction. Additional research is needed to be able to prove and support that gratitude is important to wellbeing and social life (McCullough, Emmons, \& Tsang, 2002).

In another hand, we are interesting in to study if the relationship between gratitude and life satisfaction differ by gender. Results corroborate this argument because there are some significant differences by gender. Thus, female scores were considerably higher than male ones. Froh et al. (2009) found similar results. Also, the association between gratitude and life satisfaction in females was affected in a negative way. Females with low negative effect scores were found to be more likely to attain greater life satisfaction than males. These data are similar to those obtained by Sun and Kong (2013) where "a positive effect may be a significant resource for males whereas negative effect may be a significant resource for females" (p.1367). These results could be explained in two ways. First, perhaps, these differences by gender could reflect cultural disparities and this is an area that needs further exploration (Sun \& Kong, 2013). Second, men could think that expressing gratitude may diminish their masculinity and their social status (Froh et al., 2009; Levant \& Kopeck, 1995).

Additional limitations in the current study should be taken into account in future works. The first limitation is cross-sectional, so that its results must be processed with caution. The second limitation is that this study was the use of self-report methodology, for although the measures were selected for their good reliability and validity, it is necessary to include methods for evaluation which measure some subjective aspects. The third limitation is sample sizes which were relatively small. Finally, the fourth limitation is that the study group consisted of high numbers of university students all of them of Spanish background and culture, which limits the generalization of the data.

Although some progress has been made towards understanding how gratitude affects life satisfaction, many important questions remain to be asked. For example, if there are individual cases, circumstances, situations (Fredrickson, 1998, 2001; Layous \& Lyubomirsky, 2014) and culture differences (Boehm, Lyubomirsky, \& Sheldon, 2011) which interact with the relationship between gratitude and life satisfaction. Furthermore, we need to investigate if in this association there are different meanings by gender. It is also important to know the exact cognitive mechanism of these effects. There is a need to find out costs associated with gratitude. Future research may offer suggestions about how gratitude might enhance life satisfaction (Emmons \& McCullough, 2003; Watkins, Woodward, Stone, \& Kolts, 2003 p. 449), indicating intellectual, social or psychical resources (Froh et al., 2009). Perhaps, the relationship between gratitude and life satisfaction could be reversed by the worldwide financial crisis. Therefore, in Spain, there is a need for further research into this relationship. Also, it future research should study the potential different processes and internal mechanisms involve in this connection between gratitude and life satisfaction (Sun \& Kong, 2013). On other hand, the direction of the causality between gratitude and life satisfaction is not clear in Spain, so it is necessary to research if gratitude leads to life satisfaction, has a mediated effect and provides a reciprocal model.

To sum up, the present study adds to the knowledge by investigating reciprocal causality, due to the fact that 
gratitude plays a causal role in the life satisfaction of Spanish university undergraduates. Thus, we found that gratitude is linked to life satisfaction and consequently it is necessary to adopt gratitude as an important habit and attitude (Layous \& Lyubomirsky, 2014). So, this research has been demonstrated that gratitude could be a contri-

\section{References}

Algoe, S. B., Hadit, J., \& Gablle, S. L. (2008). Beyond reciprocity: Gratitude and relationships in everyday life. Emotion, 8, 425-429.

Bertocci, P. A., \& Millard, R. M. (1963). Personality and the good: Psychological and ethical perspectives. New York: McKay.

Boehm, J. K., Lyubomirsky, S., \& Sheldon, K. M. (2011). A longitudinal experimental study comparing the effectiveness of happinessenhancing strategies in Anglo-Americans and Asian Americans. Cognition \& Emotion, 25, 1263-1272.

Bono, G., Emmons, R. A., \& McCullough, M. E. (2004). Gratitude in practice and the practice of gratitude. In P. A. Linley \& S. Joseph (Eds.), Positive psychology in practice (pp. 464-481). Hoboken, NJ, US: John Wiley $\&$ Sons Inc.

Bono, G., \& Froh, J. J. (2009). Gratitude in school: Benefits to students and schools. En R. Gilman, E. S. Huebner, \& M. Furlong (Eds.), Handbook of positive psychology in the schools: Promoting wellness in children and youth (pp.77-88). Hillsdale, NJ: Lawrence Erlbaum.

Chen, L. H., Chen, M. Y., \& Tsai, Y. M. (2012). Does gratitude always work? Ambivalence over emotional expression inhibits the beneficial effect of gratitude on well-being. International Journal of Psychology, 47, 381-392.

Diener, E. (1984). Subjective well-being. Psychological Bulletin, 95, 542-575.

Diener, E., Emmons, R. A., Larsen, R. J., \& Griffin, S. (1985). The satisfaction whit life scale. Journal of Personality Assessment, 49, 1, 71-75.

Diener, E., Oishi, S., \& Lucas, R. E. (2003). Personality, culture, and subjective well-being: Emotional and cognitive evaluation of life. Annual Review of Psychology, 54, 403-425.

Emmons, R. A., \& Crumpler, C. A. (2000). Gratitude as a human strength: Appraising the evidence. Journal of Social and Clinical Psychology, 19, 5669.

Emmons, R. A., \& McCullough, M. E. (2003). Counting blessings versus burdens: An experimental research of gratitude and subjective wellbeing in daily life. Journal of Personality and Social Psychology, 84, 377-389.

Emmons, R. A., McCullough, M. E., \& Tsang, J. (2003). The measurement of gratitude. In S. Lopez \& C. R. Snyder (Eds.), Handbook of positive psychology assessment (pp. 327-341). Washington, DC: American Psychological Association.

Emmons, R. A., \& Shelton, C. M. (2002). Gratitude and the science of positive psychology. In C.R. Snyder, \& S.J. López (Eds.), Handbook of positive psychology. New York: Oxford University Press.

Fagley, N. S. (2012). Appreciation uniquely predicts life satisfaction above demographics, the Big 5 personality factors, and gratitude. Personality and Individual Differences, 53, 59-63.

Field, A. (2009). Discovering statistics with SPSS (2nd Ed.). London: Sage Publications.

Fredrickson, B. L. (1998). What good are positive emotions? Review of General Psychology, 2, 300-319.

Fredrickson, B. L. (2001). The role of positive emotions in positive psychology: The broaden-and build theory of positive emotions. American Psychologist, 56, 218-226.

Froh, J., Yurkewicz, C., \& Kashadan, T. (2009). Gratitude and subjective well-being in early adolescences: Examining gender differences. Journal of Adolescence, 32, 633-650.

Gallup, G. H. J. (1998). Thankfulness America's saving grace. Paper presented at the national Day of Prayer Breakfast, Thanks-Giving Square, Dallas, TX.

Kashcan, T. B., Uswatte, G., \& Julian, T. (2006). Gratitude and hedonic and eudaimonic well-being in Vietnam War veterans. Behaviour Research and Therapy, 44, 177-199. bution to understand of life satisfaction. Furthermore, teaching human beings to be grateful may be a new strategy for life satisfaction, since "gratitude may be an important component of the good life" (Watkins et al., 2003 , p. 449) and only future research will clarify this question.
Lambert, N. M., Clark, M. S., Durtschi, J., Fincham, F. D., \& Graham, S. M. (2010). Benefits of expressing gratitude: Expressing gratitude to a partner changes one's view of the relationship. Psychological Science, 21 , 574-580.

Lambert, N. M., Graham, S. M., \& Fincham, F. D. (2009). A prototype analysis of gratitude: Varieties of gratitude experiences. Personality Social Psychology Bulletin, 35, 1193-1207.

Lane, J., \& Anderson, N. H. (1976). Integration of intention and outcome in moral judgment. Memory and Cognition, 4, 1-5.

Lavy, S., \& Littman-Ovadia, H. (2011). All you need is love? Strengths mediate the negative associations between attachment orientations and life satisfaction. Personality and Individual Differences, 50, 1050-1055.

Layous, K., \& Lyubomirsky, S. (2014). Benefits, Mechanisms, new directions for teaching gratitude to children. School Psychology Review, 43, 2 , 153-159.

Lazarus, R. S., \& Lazarus, B. N. (1994). Passion and reason: Making sense of our emotion. New York: Oxford University Press.

Levant, R. F., \& Kopecky, G. (1995). Masculinity, reconstructed. New York: Dutton.

Lyubomirsky, S., \& Layous, K. (2013). How do simple positive activities increase well-being? Current directions in Psychological Science, 22, 1, 57-62.

Lyubomirsky, S., Dickerhoof, R., Boehm, J. K., \& Sheldon, K. M. (2011). Becoming happier takes both a will and a proper way: An experimental longitudinal intervention to boost well-being. Emotion, 11, 391-402.

Lyubomirsky, S., Sheldon, K. M., \& Schkade, D. (2005). Pursuing happiness: The architecture of sustainable change. Review of General Psychology, 9, 111-131.

McCulloguh, M. E., Emmons, R. A., \& Tsang, J. (2002). The grateful disposition: A conceptual and empirical topography. Journal of Personality and Social Psychology, 82, 112-127.

McCullough, M. E., Kilpatrick, S., Emmons, R. A., \& Larson, D. (2001). Is gratitude a moral affect? Psychological Bulletin, 127, 249-266.

McCullough, M. E., Tsang, J. A., \& Emmons, R. A. (2004). Gratitude in intermediate affective terrain: Links of grateful moods to individual differences and daily emotional experience. Journal of Personality and Social Psychology, 86, 295-309.

Naito, T., Wangwan, J., \& Tani, M. (2005). Gratitude in university students in Japan and Thailand. Journal of Cross Cultural Psychology, 36, 247-263.

Pavot, W., \& Diener, E. (1993). Review of the satisfaction with life scale. Psychological Assessment, 5, 164-172.

Peterson, C., \& Seligman, M. E. P. (2004). Character strengths and virtues: A handbook and classification. Washington, DC: American Psychological Association.

Rosenberg, E. L. (1998). Levels of analysis and the organization of affect. Review of General Psychology, 2, 247-270.

Sansone, R. A., \& Sansone, L. A. (2010). Gratitude and well-being: The benefits of appreciation. Psychiatry, 7, 11, 18-22.

Seligman, M. E. P. (2002). Authentic happiness: Using the new positive psycholog to realize your potential for lasting fulfillment. New York: Free Press.

Seligman, M. E. P., Steen, T. A., Park, N., \& Peterson, C. (2005). Positive psychology progress: Empirical validation of interventions. American Psychologist, 60, 410-421.

Sun, P., \& Kong, F. (2013). Affective mediators of the influence of gratitude on Life satisfaction in late adolescence. Social Indicators Research, 114, 1361-1369.

Toepfer, S. M., Cichy, K., \& Peters, P. (2012). Letters of gratitude: Further evidence for author benefits. Journal of Happiness Studies, 13, 187-201. 
Watkins, P. C. (2004). Gratitude and subjective well-being. In R. A. Emmons \& M. E. McCullough (Eds.), The psychology of gratitude (pp. 167194). New York: Oxford University Press.

Watkins, P. C., Woodward, K., Stone, T., \& Kolts, R. (2003). Gratitude and happiness: Development of a measure of gratitude, and relationship with subjective well-being. Social Behavior and Personality, 31, 432-452.

Wood, A.M., Fresh, J.J., \& Geraghty, A.W. (2010). Gratitude and wellbeing: A review and theoretical integration. Clinical Psychology Review, 30, 890-905

Wood, A. M., Joseph, S., \& Linley, P. A. (2007a). Coping style as a psychological resource of grateful people. Journal of Social and Clinical Psychology, 26, 1076-1093.
Wood, A. M., Joseph, S., \& Linley, P. A. (2007b). Gratitude: The parent of all virtues. The Psychologist, 20, 18-21.

Wood, A. M., Joseph, S., \& Maltby, J. (2009). Gratitude predict psychological well-being above the big five facets. Personality and Individual differences, 46, 443-447.

Wood, A. M., Maltby, J., Gillett, R., Linley, P. A., \& Joseph, S. (2008). The role of gratitude in the development of social support, stress and depression: Two longitudinal studies. Journal of Research in Personality, 42, 854-871.

(Article received: 11-05-2015; revised: 05-12-2015; accepted: 07-03-2016) 